\title{
Gastrointestinal stromal tumours: Consensus statement on diagnosis and treatment
}

\author{
Martin E Blackstein MD PhD FRCPC FACP ${ }^{1}$, Jean-Yves Blay MD PhD², Christopher Corless MD PhD ${ }^{3}$, \\ David K Driman MBChB FRCPC ${ }^{4}$, Robert Riddell MD FRCPC ${ }^{1}$, Denis Soulières MD FRCPS ${ }^{5}$, \\ Carol J Swallow MD PhD FRCSC FACS ${ }^{1}$, Shailendra Verma MD FRCPC ${ }^{6}$, \\ on behalf of the Canadian Advisory Committee on GIST*
}

\begin{abstract}
ME Blackstein, J-Y Blay, C Corless, et al; on behalf of the Canadian Advisory Committee on GIST. Gastrointestinal stromal tumours: Consensus statement on diagnosis and treatment. Can J Gastroenterol 2006;20(3):157-163.
\end{abstract}

In the multidisciplinary management of gastrointestinal stromal tumours (GISTs), there is a need to coordinate the efforts of pathology, radiology, surgery and oncology. Surgery is the mainstay for resectable nonmetastatic GISTs, but virtually all GISTs are associated with a risk of metastasis. Imatinib $400 \mathrm{mg} /$ day with or without surgery is the recommended first-line treatment for recurrent or metastatic GIST; a higher dose may be considered in patients who progress, develop secondary resistance or present with specific genotypic characteristics. Adjuvant or neoadjuvant imatinib is not advised for resectable nonmetastatic GISTs. Neoadjuvant imatinib may be considered when surgery would result in significant morbidity or loss of organ function. Follow-up computed tomography imaging is recommended every three to six months for at least five years. Patients with metastatic disease should be continued on imatinib due to the high risk of recurrence on discontinuation of therapy. Treatment should be continued until there is progression or intolerable adverse effects. If dose escalation with imatinib fails, a clinical trial with novel agents alone or in combination may be considered. The present recommendations were developed at a surgical subcommittee meeting and a subsequent full Advisory Committee meeting held in Toronto, Ontario, in April 2005, under the sponsorship of Novartis Pharmaceuticals Canada Inc.

Key Words: Consensus; Gastrointestinal stromal tumour; Imatinib; Oncology; Treatment

Castrointestinal stromal tumours (GISTs) are the most com-

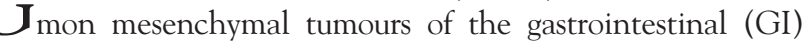
tract, representing approximately $0.2 \%$ of all GI tumours. They are believed to arise from, or share a common stem cell with, the interstitial cells of Cajal. GISTs are found primarily in the stomach $(60 \%$ to $70 \%$ of cases) and small intestine $(30 \%)$, but may also occur in the colon/rectum and esophagus $(1,2)$. GISTs have characteristic histological and immunohistochemical features. Most display a spindle cell-type histology, although epithelioid or mixed cell-type patterns have also been described (1).

\section{Tumeurs stromales de l'appareil digestif : Énoncé consensuel sur le diagnostic et le traitement}

Dans la prise en charge pluridisciplinaire des tumeurs stromales de l'appareil digestif (TSAD), les approches anatomopathologiques, radiologiques, chirurgicales et oncologiques doivent être concertées. La chirurgie forme la base du traitement des TSAD non métastatiques et résécables, mais pour ainsi dire toutes les TSAD sont associées à un risque de métastases. À raison de 400 mg/jour, avec ou sans chirurgie, l'imatinib est le traitement de première intention recommandé dans les cas de TSAD récurrentes ou métastatiques. Une dose plus forte peut être envisagée chez les patients dont la maladie progresse, qui développent une résistance secondaire ou qui présentent des caractéristiques génotypiques spécifiques. Il n'est pas à conseiller d'administrer l'imatinib en traitement adjuvant ou néo-adjuvant pour les TSAD non métastatiques résécables. L'imatinib néo-adjuvant peut être considéré lorsque la chirurgie risque d'entraîner une morbidité importante ou la perte de fonction d'un organe. Une tomodensitométrie de suivi est recommandée tous les trois à six mois, pendant au moins cinq ans. Les patients qui présentent une maladie métastatique doivent continuer de prendre l'imatinib en raison du risque élevé de récurrence à l'arrêt du traitement. Le traitement doit être maintenu jusqu'à ce que la maladie se remette à progresser ou jusqu'à ce que les effets indésirables soient devenus intolérables. Si l'augmentation de la dose d'imatinib ne donne pas de résultats, on peut faire l'essai clinique de nouveaux agents, seuls ou en association. Les présentes recommandations ont été élaborées lors de la réunion d'un sous-comité pour la chirurgie, qui a été suivie d'une rencontre du comité consultatif complet, à Toronto, Ontario, en avril 2005, avec le soutien de Novartis Pharmaceuticals Canada Inc.

The incidence of GIST is not well established due to a previous lack of pathological criteria and more recent changes in nomenclature. A Swedish study (3) has estimated an incidence of primary GIST of 14.5 and a prevalence of 129 per million population.

Tumour size and mitotic index have been shown to have prognostic value $(4,5)$, and are the criteria used to stratify risk in the current United States National Institutes of Health guidelines (Table 1) (6). In a large case series by Miettinen et al (7), $86 \%$ of GISTs larger than $10 \mathrm{~cm}$ and

This consensus statement is based on a meeting of experts sponsored by an educational grant from Novartis Pharmaceuticals Canada Inc. It is not a consensus statement from the Canadian Association of Gastroenterology or the Canadian Association for the Study of the Liver

${ }^{1}$ Mount Sinai Hospital, Toronto, Ontario; ${ }^{2}$ Université Claude Bernard Lyon, Villeurbanne, France Eु EORTC STBSG; ${ }^{3}$ Oregon Health $\mathcal{E}$

Science University, Portland, Oregon, USA; ${ }^{4}$ University of Western Ontario, London, Ontario; ${ }^{5}$ Centre Hospitalier de l'Université de

Montréal, Montreal, Quebec; ${ }^{6}$ Ottawa Hospital Regional Cancer Centre, Ottawa, Ontario; *See appendix

Correspondence: Dr Martin E Blackstein, Medical Oncology Unit, Mount Sinai Hospital, 600 University Avenue, Suite 1222, Toronto, Ontario

M5G 1X5. Telephone 416-586-5371, fax 416-586-5165, e-mail martin.blackstein@utoronto.ca

Received for publication December 4, 2005. Accepted December 12, 2005 


\section{TABLE 1}

Risk stratification of gastrointestinal stromal tumours

\begin{tabular}{lcc}
\hline Risk & Size $\mathbf{( c m )}$ & Mitotic count (per 50 HPF) \\
\hline Very low & $<2$ & $<5$ \\
Low & $2-5$ & $<5$ \\
Intermediate & $<5$ & $6-10$ \\
& $5-10$ & $<5$ \\
High & $>5$ & $>5$ \\
& $>10$ & Any mitotic rate \\
& Any size & $>10$
\end{tabular}

Data from reference 6. HPF High-power field

with more than five mitoses/50 high-power fields (HPF) metastasized compared with $2 \%$ to $3 \%$ of tumours smaller than $10 \mathrm{~cm}$ and with fewer than five mitoses/50 HPF. The prevalences of the various risk strata are estimated to be 30.9 per million for high risk/malignant (24\%), 24.2 per million for intermediate risk (19\%) and 74.1 per million for low risk/very low risk (57\%) (3). GISTs that were formerly classified as benign are now known to have malignant potential (8); therefore, all GISTs should be stratified for risk of recurrence.

Historically, long-term outcomes for metastatic GIST were poor. Surgical resection remains the cornerstone of therapy for GIST but recurrence is common. GISTs are resistant to conventional chemotherapy and radiation therapy; unresectable GISTS were generally considered to be untreatable before the advent of molecular-targeted therapy with imatinib mesylate. In an analysis of cases identified between 1983 and 2000, Nilsson et al (3) reported that 44\% of symptomatic, clinically detected GISTs were either high risk or malignant, with median survival of 3.4 years and 1.4 years, respectively.

The treatment of advanced GIST was dramatically altered with the advent of imatinib, a potent and selective inhibitor of tyrosine kinase (TK)-signalling enzymes such as KIT, plateletderived growth factor receptor (PDGFR) and ABL. Most GISTs exhibit activating mutations of the KIT or PDGFRalpha (A) $(9,10)$. Approximately $95 \%$ of the tumours express KIT protein (CD117) (9). A majority of GISTs will be found to have mutations in the KIT gene, which are in-frame and result in isoforms with constitutive kinase activity but do not necessarily explain the overexpression of the molecule $(11,12)$. Activation occurs most commonly in the membrane region, with mutations in exon 11 (approximately $70 \%$ of GISTs) or exon 9 (approximately 10\%) domains of the receptor (11). Less common are mutations occurring in the TK domain (exons 13 and 17) (13). Approximately 5\% to 7\% of GISTs have mutations in the PDGFRA gene in domains with high similarity to those found in the KIT gene (10).

In a phase I study of imatinib (400 mg to $1000 \mathrm{mg}$ per day in 35 patients with advanced GIST), stable disease (13 patients) or a partial response (19 patients) was achieved in $91 \%$ of subjects at 10 -month follow-up (14). The phase III North American Sarcoma Intergroup trial, which included the United States cooperative oncology groups and the National Cancer Institute of Canada Sarcoma Group, reported a 71\% progression-free survival and $86 \%$ overall survival at 12 months in patients with advanced GIST treated with imatinib $400 \mathrm{mg} /$ day (15).

Response to imatinib is positively correlated with exon 11 mutations; the reported one-year survival in advanced GIST is estimated to be approximately $90 \%$ (16). Response is somewhat reduced in patients with an exon 9 mutation. Blackstein et al (17) have recently reported that the $5 \%$ of GISTs that are KIT-negative may demonstrate a partial response to imatinib $400 \mathrm{mg} /$ day to $800 \mathrm{mg} /$ day, warranting a therapeutic trial of imatinib regardless of CD117 expression.

To address the rapid changes in GIST management resulting from imatinib therapy, clinical practice guidelines have recently been published by the United States National Comprehensive Cancer Network (NCCN) (18) and the European Society of Medical Oncology (ESMO) (19).

The Canadian Advisory Committee on GIST was formed with an unrestricted grant from Novartis Pharmaceuticals Canada Inc to review the growing body of data on the pathogenesis, pathology and treatment of GIST, and to address treatment issues pertinent to Canadian clinical practice. Following the Canadian Advisory Committee interim report in 2004 (20), the Pathology and Surgical-Oncology Subcommittees developed recommendations, which were presented to the full Committee of medical oncologists, pathologists, surgeons and radiologists in April 2005. The following is the group's updated consensus on the diagnosis and treatment of metastatic and nonmetastatic GIST.

\section{CONSENSUS RECOMMENDATIONS}

A multidisciplinary approach, involving pathology, radiology, surgical oncology and medical oncology, is needed to optimize the management of GIST.

\section{Pathology}

GISTs typically present as a single tumour nodule; infrequently, multiple nodules may be present. Individual small tumours appear well-circumscribed. Histologically, GISTs are most commonly composed of spindle cells arranged in short fascicles or whorls; occasionally, an epithelioid pattern with a diffuse or nested arrangement, or a mixture of both, may be seen. Tumour cells appear uniform and oval-shaped, with indistinct cell borders, fine chromatin in the nuclei and inconspicuous nucleoli. In approximately $10 \%$ of GISTs, fibrillary or hyaline eosinophilic structures (skeinoid fibres) can be visualized (21). Necrosis, mucosal invasion and mitotic index are adverse prognostic factors.

\section{Recommendations}

1. The pathology report should record the location and maximum size of the tumour, as well as the margin status. For microscopic examination, it is recommended that one tissue block be submitted for each $1 \mathrm{~cm}$ size of the tumour, with closest margins and adjacent tissue included in the sampling. The general description should record the cellularity of the tumour (low/moderate/high), the degree of cytological atypia (minimal/moderate/marked) and morphology (spindled/epithelioid/mixed). Features of aggression to be reported include necrosis, invasion of the lamina propria/mucosa, presence and site of metastases, status of margins and index of proliferative activity (mitotic count per $50 \mathrm{HPF}$ ); assessment of nuclear proliferation with $\mathrm{Ki} 67 / \mathrm{Mib}-1$ is optional.

2. An immunohistochemical profile is important to confirm the diagnosis, to rule out morphological mimics and to assess the potential response to imatinib treatment. The 
recommended immunohistochemical panel should include vimentin, CD117, CD34, smooth muscle actin, S100 protein and desmin (Table 2). Approximately 95\% of GISTs are positive for $\mathrm{CD} 117,60 \%$ to $70 \%$ are positive for CD34, 30\% to $40 \%$ are positive for smooth muscle actin, $5 \%$ are positive for $\mathrm{S} 100$ protein and $1 \%$ to $2 \%$ are positive for desmin. There is evidence that protein kinase Ctheta antibody may also be useful to differentiate GISTs from GIST mimickers (22).

3. Mutational analysis at an expert centre can be done to confirm a diagnosis of GIST. In cases of a doubtful diagnosis of GIST after histology and immunohistochemical profiling, mutational analysis can be done to help diagnose a GIST when a mutation is present. It should be noted that CD117 is also positive in melanomas and pecomas (perivascular epitheliod cell tumour) which can also arise in the intestinal tract. However, a growing body of evidence suggests that all cases should be considered for genotyping to guide the clinical management (type of therapy, dosing issues) of patients with GIST.

4. Approximately $5 \%$ of GISTs are CD117-negative. If such a tumour is suspected, it should be referred for mutational analysis of the KIT and PDGFRA genes (23). It should be noted that a subset of CD117-negative GISTs may have imatinib-sensitive mutations $(24,25)$.

5. Synoptic reporting is advised and should include the site and size of the tumour, the mitotic index, CD117 immunoreactivity, margin status, site(s) of metastases and a statement regarding the likely biological behaviour, using the United States National Institutes of Health guidelines (Table 1), when resection for cure has been carried out.

\section{Imaging}

\section{Recommendations}

1. The recommended imaging modalities are computed tomography (CT), magnetic resonance imaging (MRI) and fluorine-18-fluoro-deoxyglucose positron emission tomography (FDG-PET), if available (26). The optimal approach is a combination of PET and CT, which more precisely delineates lesions, notably in early-stage disease, and has been shown to provide additional prognostic information than either modality alone (27).

2. Small tumours found incidentally on endoscopy should be evaluated with CT or endoscopic ultrasound. Unenhanced CT is generally useful to detect most lesions and for detecting intratumoural hemorrhage. Triphasic imaging is required to avoid misinterpretation of hepatic lesions that appear following imatinib treatment, and which may not represent new or progressive disease. MRI is generally preferred for preoperative staging of rectal GISTs. FDG-PET, if available, is advised when information on early tumour response to imatinib is needed, in particular to detect primary resistance of borderline resectable GISTs so that timely resection can be scheduled before progression occurs.

3. Treatment response to imatinib should be classified according to Response Evaluation Criteria In Solid Tumors (RECIST) guidelines (27), which require measurement of individual tumours at baseline. Changes in tumour size over subsequent serial imaging should be noted.

4. Tumour size alone has been reported to be an unreliable indicator of early response to imatinib (28). It is also

\begin{tabular}{|c|c|c|}
\hline Antibody & Per cent positive & Immunoreactive neoplasms \\
\hline Vimentin & 100 & Mesenchymal tumours \\
\hline CD117 & 95 & GISTs, melanoma, pecoma \\
\hline CD34 & 60 to 70 & $\begin{array}{l}\text { Solitary fibrous tumours, spindle-cell } \\
\text { lipoma, peripheral nerve sheath, } \\
\text { vascular tumours }\end{array}$ \\
\hline $\begin{array}{l}\text { Smooth muscle } \\
\text { actin }\end{array}$ & 30 to 40 & Smooth muscle, myofibroblastic tumours \\
\hline S100 protein & 5 & $\begin{array}{l}\text { Melanocytic, peripheral nerve sheath, } \\
\text { granular cell tumours }\end{array}$ \\
\hline Desmin & 1 to 2 & Smooth muscle tumours \\
\hline
\end{tabular}

GIST Gastrointestinal stromal tumour

important to note changes in tissue characteristics (eg, decreased tumour density) and morphology on CT or MRI. Cystic degeneration on CT during imatinib therapy may also be misidentified as the development of new lesions (29). Finally, qualitative imaging assessment is sometimes required for the identification of progression even in the absence of increased tumour volume: a growing nodule within a stable mass on contrast-enhanced CT may be an early indicator of disease progression (30). Therefore, a combination of RECIST guidelines and qualitative changes is the optimal method of assessing treatment response and disease progression.

5. Follow-up CT imaging is recommended every three to six months for a minimum of five years after resection. Imaging every three months is recommended while the patient continues to receive active therapy for advanced GIST. CT and FDG-PET are the preferred methods of assessing imatinib response $(28,31,32)$. At two-week follow-up, a $10 \%$ decrease in size or a $15 \%$ decrease in tumour density on CT, or an absence of uptake on PET, is predictive of a good response $(18,32)$.

6. Imatinib should be continued even in PET-negative tumours because viable tumour cells may still be present.

\section{Treatment of nonmetastatic GIST Recommendations: Surgery}

1. For straightforward, resectable primary lesions suspected to be GIST, preoperative biopsy is generally not recommended due to the risk of tumour hemorrhage and dissemination; this area requires further research. Core biopsy should be considered when the diagnosis remains unclear based on imaging and when therapy would be altered. If response to neoadjuvant therapy with imatinib would facilitate complete resection with improved functional outcome, core biopsy is required to confirm the diagnosis of GIST. Percutaneous fine-needle aspiration cytology is not likely to be of great value in establishing a diagnosis of GIST.

2. Surgery is currently the mainstay of therapy for resectable primary GIST when there is no evidence of metastases; resection may be appropriate before a pathological diagnosis is obtained. The goal is complete resection of visible and microscopic disease (33). Ideally, even small GISTs (smaller than $1 \mathrm{~cm}$ ) should be removed due to their potential for metastasis. Extreme care is needed when handling GISTs to 
avoid tumour rupture or spillage. En bloc resection is advised for GISTs that are adherent to nearby structures (34). The goal is to achieve negative microscopic margins; positive margins are associated with a risk of peritoneal recurrence (35). In one case series (36), the disease-specific survival rate at five years for resectable GIST was 54\%; median survival was 66 months.

3. The use of laparoscopic resection is controversial. While it is a potentially useful technique for incidental small gastric GISTs (smaller than $2 \mathrm{~cm}$ ) when the risk of tumour rupture is low, there is currently no consensus on the appropriate use of laparoscopy. Additional data are required.

4. Lymphadenectomy is not required when the diagnosis of GIST has been established.

5. Neoadjuvant imatinib should be considered for 'functionally unresectable' GIST, where surgery would result in significant morbidity or loss of organ function, with the purpose of downsizing the tumour and preserving organ function (37-39). Examples include tumours near the gastroesophageal junction that would otherwise require total gastrectomy, duodenal GIST requiring pancreaticoduodenectomy (Whipple procedure) or a low rectal GIST requiring abdominoperineal resection. Neoadjuvant imatinib, when appropriate, should be initiated promptly. Surgery should be performed, ideally in a tertiary care centre, approximately four to 12 months after initiating imatinib when maximal tumour shrinkage has been achieved. Follow-up CT scans should be performed every three months; maximal tumour shrinkage is defined as no further shrinkage on two consecutive CT scans. Because the risk of significant hemorrhage approximates $5 \%$, a surgeon should form part of the management team making the decision for neoadjuvant treatment.

6. Imatinib is recommended for borderline unresectable GIST (37). Because there is a potentially small window of opportunity before the GIST becomes unresectable in the case of primary resistance, PET scans are recommended at baseline and seven to 14 days after initiation of imatinib in these cases.

7. Imatinib is recommended for all patients with unresectable tumours $(16,40)$. In a randomized, open-label trial of 147 patients by Demetri et al (40), 54\% of subjects had a partial response and $28 \%$ had stable disease with imatinib $400 \mathrm{mg} /$ day or $600 \mathrm{mg} /$ day.

\section{Recommendations: Medical oncology}

1. There are no mature outcome data on imatinib pretreatment for resectable primary GIST (neoadjuvant) and this approach remains investigational. At present, there is no rationale or evidence to support neoadjuvant imatinib when tumour downsizing will not affect the magnitude of the surgical procedure (see recommendation 5 above). The RTOG-S0132 study will help clarify the role of neoadjuvant imatinib.

2. Adjuvant imatinib is not recommended as standard therapy for patients with localized GIST that has been resected. Two large European trials, a phase III European Organization for Research and Treatment of Cancer (EORTC) intergroup study and a phase II trial by the Scandinavian Sarcoma Group, and one North American study, ACOSOG Z9001, are now examining whether adjuvant imatinib will lower the risk of disease recurrence. All North American patients with primary tumours larger than $3 \mathrm{~cm}$ in size should be considered for inclusion in the adjuvant trial through ACOSOG or National Cancer Institute of Canada.

\section{Treatment of recurrent/metastatic disease Recommendations: Medical oncology/surgery}

1. Recurrent disease should be managed as metastatic disease.

2. Imatinib is the recommended first-line treatment in patients with recurrent or metastatic disease $(16,41)$.

3. Resectable primary GIST and resectable metastases: Treatment should include some combination of imatinib and resection of the primary tumour and metastases. Surgery is not curative but can provide symptomatic benefits and may delay tumour progression and/or the development of imatinibresistant clones. A majority of surgeons thought that imatinib should precede surgery; a full consensus was not reached on this point. It was agreed that the multimodal treatment plan should be individualized and based on multidisciplinary consultation.

4. While some patients may have a complete response or no evidence of disease either with surgery alone or with the combination of surgery and imatinib, few patients will have a complete pathological response. Therefore, ongoing postoperative imatinib is generally advised. This is controversial, however, and further study is needed to research this issue.

5. Resectable primary tumour and unresectable metastases: Imatinib is recommended as first-line treatment $(16,40)$. In some cases, initial resection of the primary tumour may be appropriate; the treatment plan should be individualized based on multidisciplinary consultation.

6. Endoscopic ultrasound-guided fine-needle aspiration biopsy is recommended for patients with unresectable or widespread metastatic disease (42).

7. Stable residual disease: Imatinib is recommended as maintenance therapy for all patients because interruption of imatinib after one year of continuous therapy has been shown in a phase III trial to be associated with a high risk of relapse (43). The role of surgery in these cases is controversial. It was generally agreed that consideration should be given to removal of resectable tumours to prevent the development of imatinib-resistant clones.

8. Limited progressive disease: Limited progressive disease is defined as any radiological evidence of limited progression within the context of otherwise stable widespread disease. Surgery should be considered to remove resistant clones; these may progress rapidly and require prompt intervention. However, repeated resections are associated with increasing morbidity. The benefit of these procedures for the patient in terms of survival improvement requires additional investigation. Radiofrequency ablation may be considered as a possible nonsurgical option.

9. Hepatic artery embolization should be considered for large resistant hepatic metastases, and may be particularly useful in the emergency management of intratumoural hemorrhage.

10.Multifocal progressive disease: Surgery is generally not advised due to the high risk of postoperative mortality and 
significant morbidity. Resection may be considered in symptomatic patients.

Medical oncology: treatment considerations

1. Dosing: The standard dose of imatinib is $400 \mathrm{mg} / \mathrm{day}$.

2. Treatment initiation: Imatinib should be initiated promptly following a diagnosis of metastatic GIST.

3. Dose escalation: Dose escalation to $400 \mathrm{mg}$ twice daily should be considered in previous imatinib responders who develop progression or secondary resistance on the lower dose. This approach has been shown to induce response in approximately one-third (mostly stable disease) of initial imatinib responders (44). The strategy may maximize treatment response and delay further progression. A dose of imatinib $400 \mathrm{mg}$ twice daily has been shown to be associated with significantly longer progression-free survival (Figure 1) (45).

4. Higher doses: Two recent studies $(46,47)$ have suggested that patients with GIST exhibiting an exon 9 mutation could benefit from a higher dose $(800 \mathrm{mg})$ at initiation of therapy. These data are based on retrospective analyses because there was no stratification for genotype before starting therapy. However, this information, combined with prior knowledge that patients with GISTs with a KIT exon 9 or a PDGFRA D842V mutation respond poorly to a dose of $400 \mathrm{mg} /$ day, is clinically significant and warrants consideration for a dose of $800 \mathrm{mg}$ at initiation of therapy for recurrent/metastatic disease.

5. Duration of imatinib: All patients with advanced GIST should receive imatinib until there is progression on the higher dose, intolerance to the regimen and/or patient refusal. Discontinuation of imatinib therapy is associated with a high risk of relapse ('flare phenomenon') of imatinibsensitive tumours (45).

6. Progression during imatinib therapy: If the patient response following a trial of imatinib of $400 \mathrm{mg}$ twice daily is inadequate, the patient should be considered for an alternative treatment in a clinical study. A phase III study has reported that imatinib-resistant patients may respond to a novel TK inhibitor, SU011248 (sunitinib) (48), which may be primarily effective for those with the KIT exon 9 mutation. Imatinib may still be required to suppress imatinib-sensitive tumours. The optimal regimen (monotherapy, combination therapy), if indicated, has not been determined.

7. Imatinib nonresponders: An alternative multimodal approach is required for primary nonresponders to imatinib. Resection may be recommended if all viable disease can be removed. Radiofrequency ablation may be an appropriate alternative to hepatic resection in some cases (49).

\section{SUMMARY STATEMENTS}

1. GIST is an uncommon malignancy. Consideration for referral of such patients to centres with a multidisciplinary approach to this disease with expertise in surgical oncology, medical oncology, radiology, pathology and support services should be given.

2. There is a need for improved detection/diagnosis of GISTs in clinical practice. Standardizing the reporting of pathological, immunohistochemical and radiological results should assist in diagnosis and in optimizing patient management and outcomes.

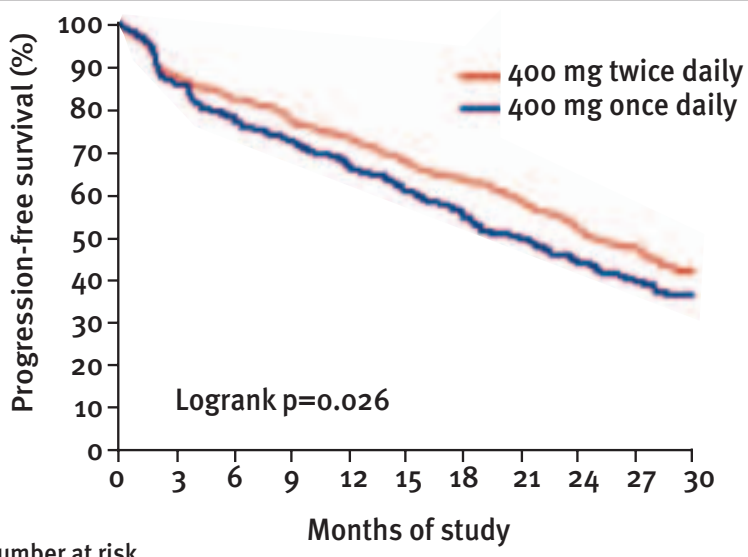

Number at risk

400 mg once daily 4734043663383072702281841277125 400 mg twice daily $473 \quad 414 \quad 388 \quad 365 \quad 343 \quad 300 \quad 266 \quad 218 \quad 14796 \quad 39$

Figure 1) Progression-free survival with imatinib $400 \mathrm{mg} /$ day versus $800 \mathrm{mg} /$ day. From reference 45 with permission

3. The recognition of CD117 expression in GISTs is an important advance in differentiating GISTs from other GI neoplasms. Over 90\% of GISTs will stain for CD117. Pathologists should be aware that CD117 is also positive in other tumours, particularly melanoma.

4. The optimal radiological approach for GISTs is a combination of CT and PET.

5. Surgery remains the principal treatment modality for resectable nonmetastatic GIST.

6. Virtually all GISTs are associated with a risk of metastasis. Any recurrence should be considered as metastatic disease.

7. Imatinib $400 \mathrm{mg} /$ day, with or without surgery as clinically appropriate, is the recommended first-line treatment for recurrent or metastatic GIST. A dose increase to $400 \mathrm{mg}$ twice daily may be considered in patients who progress on the lower dose and/or develop secondary resistance. Other medical or surgical modalities should also be considered depending on the clinical situation.

8. Higher upfront doses ( $800 \mathrm{mg} /$ day) may be considered for patients with KIT exon 9 or PDGFRA D842V mutations once molecular diagnosis becomes more readily available at diagnosis.

9. Adjuvant or neoadjuvant imatinib is not advised at this time as standard therapy for resectable nonmetastatic GIST. Neoadjuvant imatinib should be considered for 'functionally unresectable' GIST, where surgery would result in significant morbidity or loss of organ function.

10. Reporting of treatment response to imatinib should be in accordance with RECIST guidelines but should also incorporate CT changes in tumour enhancement which may better reflect response in the early treatment period.

11. Follow-up CT imaging is recommended every three to six months for a minimum of five years.

12. In patients with metastatic disease, imatinib should be continued even in complete responders to imatinib with or without surgery due to the high risk of recurrence on discontinuation of therapy. Treatment should be continued until there is progression with imatinib $400 \mathrm{mg}$ twice daily and/or intolerable adverse effects; if dose escalation with imatinib fails, a novel agent or a clinical trial may be considered. 


\section{ACKNOWLEDGEMENTS The Canadian Advisory} Committee on Gastrointestinal Stromal Tumours acknowledges the invaluable assistance of the Surgery Subcommittee in the development of this consensus statement. Subcommittee members: Carol J Swallow, MD, PhD, Mount Sinai Hospital, Toronto, Ontario (Co-chair); Steven Gallinger, MD, Mount Sinai Hospital, Toronto, Ontario (Co-chair). Members: Jean-François Bellemare, MD, Hôpital du Sacré-Cour de Montréal, Montréal, Québec; Rona E Cheifetz, MD, Vancouver Hospital \& Health Sciences Centre, Vancouver, British Columbia; Jean Couture, MD, Hôpital Charles LeMoyne, Greenfield Park, Quebec; Christopher J de Gara, MB, Cross Cancer Institute, Edmonton, Alberta; C Jay Engel, MB, London Regional Cancer Centre, London, Ontario; Ralph George, MD, Kingston Regional Cancer Centre, Kingston, Ontario; Carman A Giacomantonio, MD, Queen Elizabeth II Health Sciences Centre, Halifax, Nova Scotia; Selliah Chandra Kanthan, MB, Royal University Hospital, Saskatoon, Saskatchewan; Calvin Law, MD, Toronto Sunnybrook Regional Cancer Centre, Toronto, Ontario; Richard Létourneau, MD, Centre Hospitalier de l'Université de Montréal - St-Luc, Montréal, Québec; Peter Metrakos, MD, McGill University Health Centre, Royal Victoria Hospital, Montréal, Québec; Geoffrey A Porter, MD, Queen Elizabeth II Health Sciences Centre, Halifax, Nova Scotia; Richard Ratelle, MD, Centre Hospitalier de l'Université de Montréal - St-Luc, Montréal, Québec; Leyo Ruo, MD, University of Saskatchewan, Royal University Hospital, Saskatoon, Saskatchewan; Ved Tandan, MD, St Joseph's Healthcare, Hamilton, Ontario; Debrah Wirtzfeld, MD, Memorial University, St John's, Newfoundland.

\section{APPENDIX}

Canadian Advisory Committee on Gastrointestinal Stromal Tumours: Chair: Martin E Blackstein' MD PhD FRCPC FACP, Mt Sinai Hospital, Toronto, Ontario; Louis R Bégin, MD, Hôpital du Sacré-Coeur de Montréal, Montreal, Quebec; Jean-Yves Blay' MD PhD, Université Claude Bernard Lyon, France \& EORTC STBSG; Christopher Corless, MD PhD, Oregon Health \& Science University, Portland, Oregon, USA; David K Driman, MBChB FRCPC, University of Western Ontario, London, Ontario; Pierre Dubé, MD FRCSC, Centre Hospitalier de l'Université de Montréal, Montreal, Quebec; Alvaro Figueredo, MD, The Juravinski Cancer Clinic, Hamilton, Ontario; Massom Haider, MD, Princess Margaret Hospital, Toronto, Ontario; Korosh Khalili, MD, Princess Margaret Hospital, Toronto, Ontario; Margaret Knowling, MD FRCPC, British Columbia Cancer Agency - Vancouver Cancer Clinic, Vancouver, British Columbia; Calvin Law, MD FRCSC, Sunnybrook \& Women's College Health Sciences Centre, Toronto, Ontario; Bernard L'Espérance, MD, Hôpital du Sacré-Coeur de Montréal, Montreal, Quebec; Donald Morris, MD PhD FRCPC, Tom Baker Cancer Centre, Calgary, Alberta; Karen Mulder, MD FRCPC, Cross Cancer Institute, Department of Oncology, Edmonton, Alberta; David Owen, MD, Vancouver General Hospital, Vancouver, British Columbia; Aaron Pollett, MD, Mount Sinai Hospital, Toronto, Ontario; Robert Riddell, MD FRCPC, Mt Sinai Hospital, Toronto, Ontario; Stewart Rorke, MD FRCPC, Dr H Bliss Murphy Cancer Centre, St John's, Newfoundland; Denis Soulières, MD FRCPS, Centre Hospitalier de l'Université de Montréal, Montreal, Quebec; Carol J Swallow, MD PhD FRCSC FACS, Mt Sinai Hospital, Toronto, Ontario; Shailendra Verma, MD FRCPC, Ottawa Hospital Regional Cancer Centre, Ottawa, Ontario; Ralph Wong, MD FRCPC, St Boniface General Hospital, Winnipeg, Manitoba; Jawaid Younus, MD, London Regional Cancer Centre, London, Ontario.

\section{REFERENCES}

1. Miettinen M, Sarlomo-Rikala M, Lasota J. Gastrointestinal stromal tumours. Ann Chir Gynaecol 1998;87:278-81.

2. Hasegawa T, Matsuno Y, Shimoda T, Hirohashi S. Gastrointestinal stromal tumor: Consistent CD117 immunostaining for diagnosis, and prognostic classification based on tumor size and MIB-1 grade. Hum Pathol 2002;33:669-76.

3. Nilsson B, Bumming P, Meis-Kindblom JM, et al. Gastrointestinal stromal tumors: The incidence, prevalence, clinical course, and prognostication in the preimatinib mesylate era. Cancer 2005; 103:821-9.

4. Di Matteo G, Pescarmona E, Peparini N, et al. Histopathological features and clinical course of the gastrointestinal stromal tumors. Hepatogastroenterology 2002;49:1013-6.

5. Tornoczky T, Kalman E, Hegedus G, et al. High mitotic index associated with poor prognosis in gastrointestinal autonomic nerve tumour. Histopathology 1999;35:121-8.

6. Fletcher CD, Berman JJ, Corless C, et al. Diagnosis of gastrointestinal stromal tumors: A consensus approach. Hum Pathol 2002;33:459-65.

7. Miettinen M, Sobin LH, Lasota J. Gastrointestinal stromal tumors of the stomach: A clinicopathologic, immunohistochemical, and molecular genetic study of 1765 cases with long-term follow-up. Am J Surg Pathol 2005;29:52-68.

8. Miettinen M, Kopczynski J, Makhlouf HR, et al. Gastrointestinal stromal tumors, intramural leiomyomas, and leiomyosarcomas in the duodenum: A clinicopathologic, immunohistochemical, and molecular genetic study of 167 cases. Am J Surg Pathol 2003;27:625-41.

9. Hirota S, Isozaki K, Moriyama Y, et al. Gain-of-function mutations of c-kit in human gastrointestinal stromal tumors. Science 1998;279:577-80.

10. Heinrich MC, Corless CL, Duensing A, et al. PDGFRA activating mutations in gastrointestinal stromal tumors. Science 2003;299:708-10.

11. Rubin BP, Singer S, Tsao C, et al. KIT activation is a ubiquitous feature of gastrointestinal stromal tumors. Cancer Res 2001;61:8118-21.

12. Demetri GD. Targeting c-kit mutations in solid tumors: Scientific rationale and novel therapeutic options. Semin Oncol 2001;28:19-26.

13. Kinoshita K, Isozaki K, Hirota S, et al. c-kit gene mutation at exon 17 or 13 is very rare in sporadic gastrointestinal stromal tumors. J Gastroenterol Hepatol 2003;18:147-51.

14. van Oosterom AT, Judson IR, Verweij J, et al. Update of phase I study of imatinib (STI571) in advanced soft tissue sarcomas and gastrointestinal stromal tumors: a report of the EORTC Soft Tissue and Bone Sarcoma Group. Eur J Cancer 2002;38(suppl 5):S83-7.

15. Benjamin RS, Rankin C, Fletcher J, et al. Phase III doserandomized study of imatinib mesylate (STI 571) for GIST: Intergroup S0033 early results. Proc Am Soc Clin Oncol 2003;22:814. (Abst)

16. Dagher R, Cohen M, Williams G, et al. Approval summary: Imatinib mesylate in the treatment of metastatic and/or unresectable malignant gastrointestinal stromal tumors. Clin Cancer Res 2002;8:3034-8.

17. Blackstein ME, Rankin C, Fletcher CD, et al. Clinical benefit of imatinib (IM) in patients (pts) with metastatic gastrointestinal stromal tumors negative for expression of CD117 (KIT-GIST) in the S0033 Phase III trial. Presented at the American Association of Clinical Oncology (ASCO) annual meeting, Orlando, Florida, May 13-17, 2005. (Abst)

18. Demetri GD, Benjamin R, Blanke CD, et al. NCCN Task Force Report: Optimal management of patients with gastrointestinal stromal tumor (GIST) - expansion and update of NCCN clinical practice guidelines. JNCCN 2004;2(Suppl 1):S1-S26.

19. Blay JY, Bonvalot S, Casali P, et al. Consensus meeting for the management of gastrointestinal stromal tumors. Report of the GIST Consensus Conference of 20-21 March 2004, under the auspices of ESMO. Ann Oncol 2005;16:566-78.

20. Blackstein ME, Dube P, Fletcher JA, et al. Gastrointestinal stromal tumours: Etiology, pathology and clinical management. Can J Gastroenterol 2004;18 Suppl B:3B-8B.

21. Plaat BE, Hollema H, Molenaar WM. Soft tissue leiomyosarcomas and malignant gastrointestinal tumors: Differences in clinical outcome and expression of multidrug resistance proteins. J Clin Oncol 2000;18:3211-20. 
22. Blay P, Astudillo A, Buesa JM, et al. Protein kinase C theta is highly expressed in gastrointestinal stromal tumors but not in other mesenchymal neoplasias. Clin Cancer Res 2004;10):4089-95.

23. Debiec-Rychter M, Dumez H, Judson I, et al. Use of c-KIT/PDGFRA mutational analysis to predict the clinical response to imatinib in patients with advanced gastrointestinal stromal tumours entered on phase I and II studies of the EORTC Soft Tissue and Bone Sarcoma Group. Eur J Cancer 2004;40:689-95.

24. Bauer S, Corless CL, Heinrich MC, et al. Response to imatinib mesylate of a gastrointestinal stromal tumor with very low expression of KIT. Cancer Chemother Pharmacol 2003;51:261-5.

25. Corless CL, Schroeder A, Griffith D, et al. PDGFRA mutations in gastrointestinal stromal tumors: Frequency, spectrum and in vitro sensitivity to imatinib. J Clin Oncol 2005;23:5357-64.

26. Goerres GW, Stupp R, Barghouth G, et al. The value of PET, CT and in-line PET/CT in patients with gastrointestinal stromal tumours: long-term outcome of treatment with imatinib mesylate. Eur J Nucl Med Mol Imaging 2005;32:153-62.

27. Therasse P, Arbuck SG, Eisenhauer E, et al. New guidelines to evaluate the response to treatment in solid tumours. J Natl Cancer Inst 2000;92:205-16.

28. Choi H, Charnsangavej C, de Castro Faria S, et al. CT evaluation of the response of gastrointestinal stromal tumors after imatinib mesylate treatment: a quantitative analysis correlated with FDG PET findings. AJR Am J Roentgenol 2004;183:1619-28.

29. Linton KM, Taylor MB, Radford JA. Response evaluation in GIST treated with imatinib - misdiagnosis of disease progression on CT due to cystic change in liver metastases (abst 9047). Presented at the American Association of Clinical Oncology (ASCO) annual meeting, Orlando, Florida, May 13-17, 2005.

30. Shankar S, Vansonnenberg E, Desai J, Dipiro PJ, Van Den Abbeele A, Demetri GD. Gastrointestinal Stromal Tumor: New Nodule-withina-Mass Pattern of Recurrence after Partial Response to Imatinib Mesylate. Radiology 2005;235:892-8.

31. Stroobants S, Goeminne J, Seegers M, et al. 18FDG-Positron emission tomography for the early prediction of response in advanced soft tissue sarcoma treated with imatinib mesylate (Glivec). Eur J Cancer 2003;39:2012-20.

32. Vanel D, Albiter M, Shapeero L, et al. Role of computed tomography in the follow-up of hepatic and peritoneal metastases of GIST under imatinib mesylate treatment: A prospective study of 54 patients. Eur J Radiol 2005;54:118-23.

33. Ng EH, Pollock RE, Munsell MF, Atkinson EN, Romsdahl MM. Prognostic factors influencing survival in gastrointestinal leiomyosarcomas. Implications for surgical management and staging. Ann Surg 1992;215:68-77.

34. Crosby JA, Catton CN, Davis A, et al. Malignant gastrointestinal stromal tumors of the small intestine: A review of 50 cases from a prospective database. Ann Surg Oncol 2001;8:50-9.

35. Chen TW, Liu HD, Shyu RY, et al. Giant malignant gastrointestinal stromal tumors: recurrence and effects of treatment with STI-571. World J Gastroenterol 2005;11:260-3.

36. DeMatteo RP, Lewis JJ, Leung D, Mudan SS, Woodruff JM, Brennan MF. Two hundred gastrointestinal stromal tumors:
Recurrence patterns and prognostic factors for survival. Ann Surg 2000;231:51-8.

37. Bauer $\mathrm{S}$, Hartmann JT, Lang $\mathrm{H}$, et al. Imatinib may enable complete resection in previously unresectable or metastatic GIST. Proc Am Soc Clin Oncol 2004;23:819. (Abst)

38. Katz D, Segal A, Alberton Y, et al. Neoadjuvant imatinib for unresectable gastrointestinal stromal tumor. Anticancer Drugs 2004;15:599-602

39. Hohenberger P, Bauer S, Schneider U, et al. Tumor resection following imatinib pretreatment in GI stomal tumors (abst 3288). Presented at the 39th annual meeting of the American Society of Clinical Oncology, Chicago IL, May 31-June 3, 2003.

40. Demetri GD, von Mehren M, Blanke CD, et al. Efficacy and safety of imatinib mesylate in advanced gastrointestinal stromal tumors. N Engl J Med 2002;347:472-80.

41. Bumming P, Andersson J, Meis-Kindblom JM, et al. Neoadjuvant, adjuvant and palliative treatment of gastrointestinal stromal tumours (GIST) with imatinib: A centre-based study of 17 patients. Br J Cancer 2003;89:460-4.

42. Okubo K, Yamao K, Nakamura T, et al. Endoscopic ultrasoundguided fine-needle aspiration biopsy for the diagnosis of gastrointestinal stromal tumors in the stomach. J Gastroenterol 2004;39:747-53.

43. Blay J-Y, Berthaud P, Perol D, et al. Continuous vs. intermittent imatinib treatment in advanced GIST after one year: A prospective randomized phase III trial of the French Sarcoma Group. Proc Am Soc Clin Oncol 2004;23:815. (Abst)

44. Zalcberg JR, Verweij J, Casali PG, et al. Outcome of patients with advanced gastro-intestinal stromal tumours (GIST) crossing over to a daily imatinib dose of $800 \mathrm{mg}$ after progression on $400 \mathrm{mg}$. Eur J Cancer 2005;41:1751-7.

45. Verweij J, Casali PG, Zalcberg J, et al. Progression-free survival in gastrointestinal stromal tumours with high-dose imatinib: Randomised trial. Lancet 2004;364:1127-34.

46. Heinrich MC, Shoemaker JS, Corless CL, et al. Correlation of target kinase genotype with clinical activity of imatinib mesylate (IM) in patients with metastatic GI stromal tumors (GISTs) expressing KIT (KIT+). Proc Am Soc Clin Oncol 2005;23:3S. (Abst)

47. Ray-Coquard I, Pérol D, Bui BN, et al. Prognostic factors for progression free and overall survival in advanced GIST: Results from the BFR14 phase III trial of the French Sarcoma Group. Presented at the American Association of Clinical Oncology (ASCO) annual meeting, Orlando, Florida, May 13-17, 2005. (Abst)

48. Demetri GD, van Oosterom AT, Blackstein M, et al. Phase 3 , multicenter, randomized, double-blind, placebo-controlled trial of SU11248 in patients (pts) following failure of imatinib for metastatic GIST. Presented at the American Association of Clinical Oncology (ASCO) annual meeting, Orlando, Florida, May 13-17, 2005. (Abst)

49. Dileo P, Randhawa R, Vansonnenberg E, et al. Safety and efficacy of percutaneous radio-frequency ablation (RFA) in patients (pts) with metastatic gastrointestinal stromal tumor (GIST) with clonal evolution of lesions refractory to imatinib mesylate (IM). Proc Am Soc Clin Oncol 2004;23:818. (Abst) 


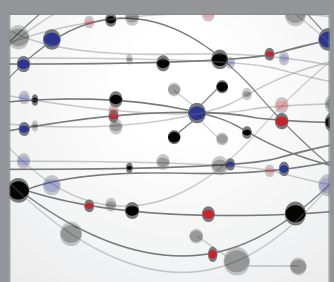

The Scientific World Journal
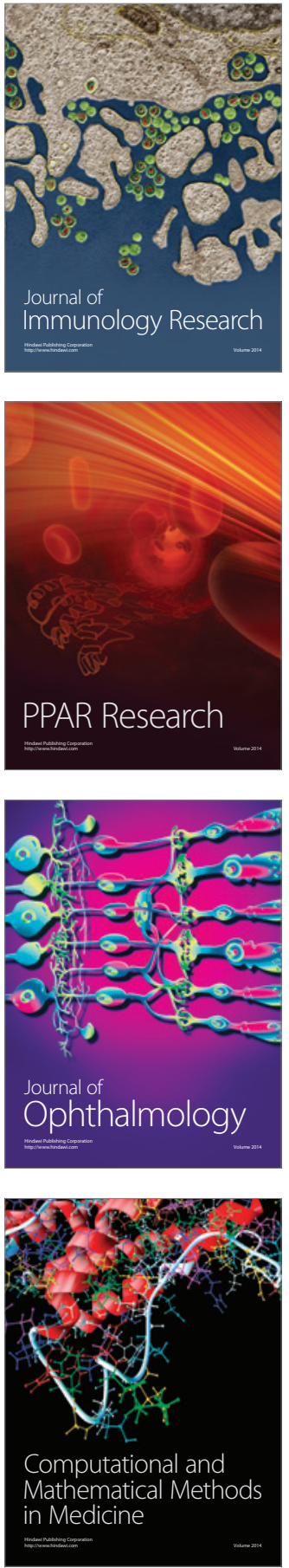

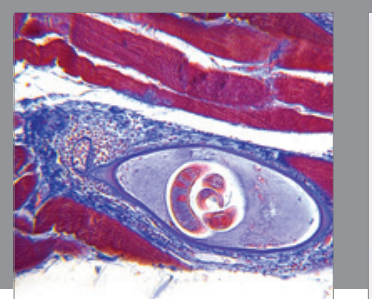

Gastroenterology Research and Practice

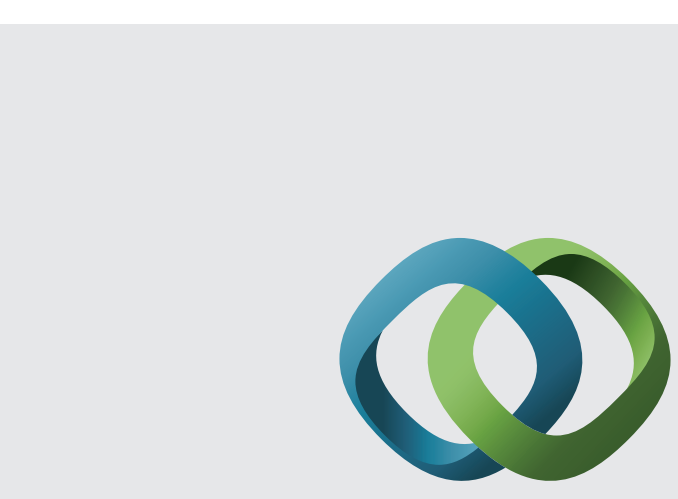

\section{Hindawi}

Submit your manuscripts at

http://www.hindawi.com
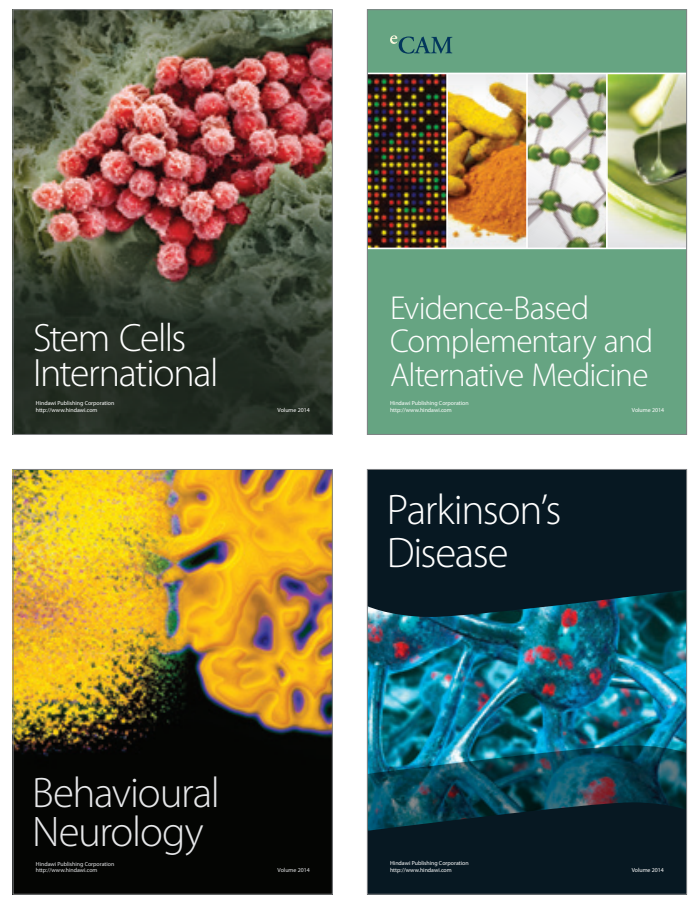
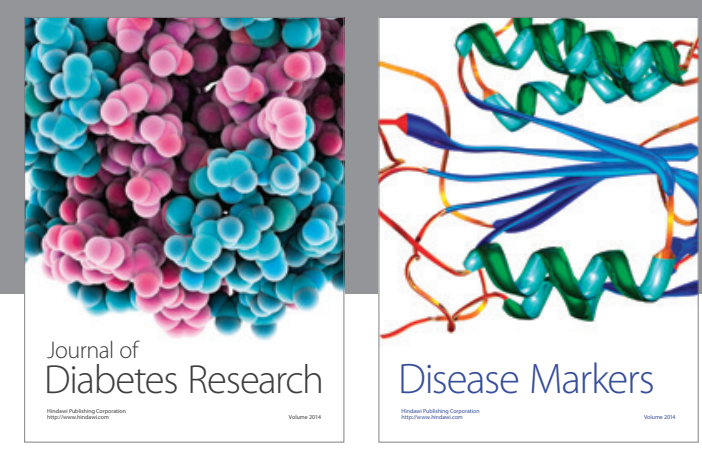

Disease Markers
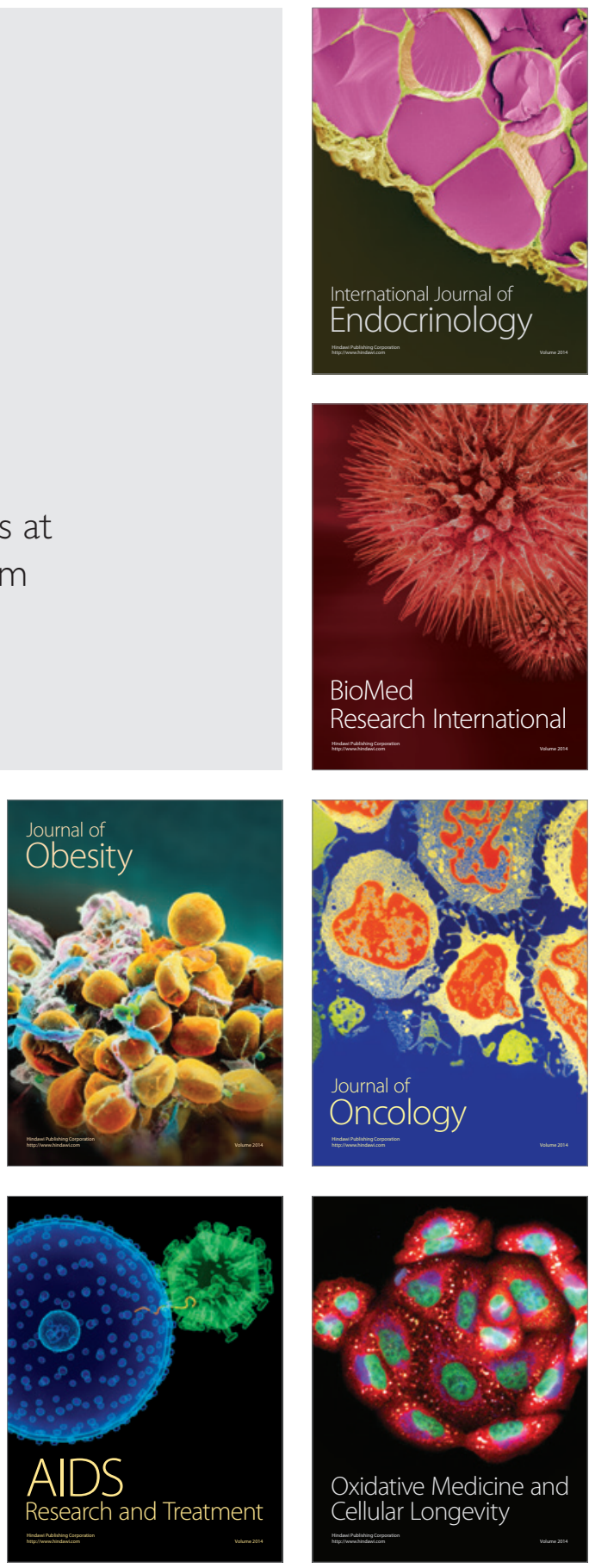